\title{
The Validity of New Memory Complaints in the Elderly
}

Peter W. Schofield, MBBS, MS, FRACP; Diane Jacobs, PhD; Karen Marder, MD, MPH; Mary Sano, PhD; Yaakov Stern, PhD

Objective: To determine the validity of new subjective memory complaints (MCs) from individuals who previously, when without dementia, denied having MCs.

Design: Prospective cohort.

Sorting: Longitudinal, community-based study of aging and dementia.

Patients: One hundred thirty-three communitydwelling elderly individuals who were part of a registry for the study of conditions related to aging in North Manhattan, NY. Patients were selected if they were initially without dementia and had completed at least 2 successive annual clinical and neuropsychological evaluations and provided their own medical history.

Main Outcome Measures: Performance on memory tests-the Buschke Selective Reminding Test and a visual memory task-and global performance on a neuropsychological test battery and clinical evaluation, by which questionable dementia or dementia was diagnosed according to a well-defined paradigm.

Results: Fifty-three subjects with MCs at the initial evaluation performed no worse on the memory test than the 80 subjects who denied MCs initially. There was a weak association between MCs and the diagnosis of questionable dementia at baseline $(P=.04)$, but this was nonsignificant after adjusting for age and education. At 1-year follow-up, 21 of the 80 without baseline MCs now reported MCs. At the follow-up evaluation, these 21 subjects performed significantly worse on the memory tests, were 5 times more likely to have significant cognitive impairment, and had shown significantly greater decline over the preceding year on several of the cognitive measures than the 59 who continued to deny MCs.

Conclusion: New MCs from individuals, who when without dementia recently denied MCs, may suggest the presence of significant impairment of memory or cognition.

Arch Neurol. 1997;54:756-759
From the Gertrude $H$. Sergievsky Center, Taub Alzheimer's Disease Research Center, and Departments of Neurology (Drs Schofield, Jacobs, Marder, Sano, and Stern) and Psychiatry (Dr Stern), College of Physicians and Surgeons, New York, NY.

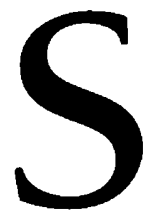

UBJECTIVE memory complaints (MCs) are among the earliest presenting symptoms of Alzheimer disease $(\mathrm{AD})^{1}$; however, many individuals with MCs are cognitively normal when evaluated by formal cognitive tests. ${ }^{2-11}$ Indeed, the validity of MCs has been questioned by investigators ${ }^{2,3,5}$ who have found little or no relationship between MCs and memory performance on objective tests within study populations. It would be valuable, therefore, to identify any specific circumstances in which MCs might provide valid information to the clinician.

Christensen ${ }^{12}$ found objective memory deficits in individuals who reported memory problems of recent onset and who considered their memory to be worse than that of their peers. Other investigators have found that MCs are associated with depression $^{6,13,14}$ or certain personality characteristics rather than memory performance. ${ }^{3,15,16}$ These observations suggested to us the possibility that new MCs from individuals who previously denied having
MCs may perhaps be more valid. We reasoned that individuals who had previously denied having MCs were unlikely to have the personality type hypothetically associated with cognitive complaints; furthermore, the recency of onset of MCs in these individuals could be established beyond doubt. New MCs from subjects who previously denied having memory problems might thus reflect significantly impaired memory performance, relative to appropriate control subjects without MCs. We used data from a longitudinal study of aging and dementia to test this hypothesis.

\section{RESULTS}

One hundred thirty-three subjects met entry criteria (Table 1). At baseline, 53 subjects gave a history of MCs and 80 denied having MCs. There were no group differences between subjects with MCs and those without MCs with respect to gender, age, education, language or performance on the Total Recall Test $(P=.67)$, Delayed Recall Test $(P=.66)$, or the Vi- 


\section{SUBJECTS AND METHODS}

\section{SUBJECTS SOURCE AND SELECTION}

Subjects were drawn from a registry of aging and neurological conditions in North Manhattan, NY, ${ }^{17}$ created to identify individuals older than 60 years at risk for dementia. Nursing homes, home health care agencies, private practitioners, hospital admission, and discharge lists were canvassed to identify individuals who were invited to undergo a brief cognitive screening examination ${ }^{18}$ modified from the Comprehensive Assessment and Referral Interview. ${ }^{19}$ All subjects scoring above 2 on the screening examination and a randomly selected sample of approximately $25 \%$ of those who scored 2 or less on the screening test were referred to a clinical evaluation team for a comprehensive clinical assessment, which included general medical and neurological assessments and a battery of neuropsychological tests described herein. These evaluations, which were repeated annually, have been published.$^{20}$ Subjects who entered the study were followed up for 5 years. At each annual clinical evaluation subjects were asked, "Do you have problems with your memory?" The answer was recorded as yes or no. The source of the history was recorded-subject alone, subject and informant, or informant alone.

\section{Neuropsychological Evaluation}

Testing was performed by trained testers and usually took about 1 hour to complete. It was performed in Spanish or English according to the subjects' wishes. All subjects had the same standardized evaluation at each visit.
Verbal memory was assessed using the Buschke Selective Reminding Test (SRT). ${ }^{21}$ Short-term verbal memory was assessed by the Total Recall Test from the SRT and longterm verbal memory was assessed by the Delayed Recall Test after 15 minutes of words from the SRT. Nonverbal memory was assessed with a multiple choice recognition version of the Benton Visual Retention Test (henceforth referred to as Visual Recognition Test). ${ }^{22}$ Thus, 3 memory domains were evaluated: verbal, short-term and long-term, and visual.

Briefly, the other cognitive functions we assessed (and the tests we used to assess them) were orientation (the 10 orientation items from the Mini-Mental State Examination ${ }^{23}$ ), both verbal (the similarities subtest of the Wechsler Adult Intelligence Scale-Revised ${ }^{24}$ ) and nonverbal (the identities and oddities subtest of the Mattis Dementia Rating Scale ${ }^{25}$ ) abstract reasoning, language (items from referenced tests ${ }^{26-28}$ ), construction (the Rosen Drawing Test ${ }^{29}$ ), and visuoperception. ${ }^{22}$

\section{Dementia Diagnosis}

Neuropsychological test scores were compared with cutoff scores derived from pilot study data. ${ }^{20}$ Dementia was diagnosed when subjects scored below cutoff scores in at least 2 of the 3 memory domains and below cutoff scores in at least 2 domains of nonmemory cognitive functions, and in addition had historical evidence of functional or occupational impairment because of cognitive decline.

Information from the medical and neuropsychological evaluations were reviewed at a conference of study neurologists and neuropsychologists. All data, including

\section{Continued on next page}

sual Recognition Test $(P=.23)$. These findings are consistent with studies ${ }^{2,3,5}$ suggesting that MCs do not predict memory performance. In a $\chi^{2}$ analysis MCs were weakly associated with questionable dementia $(P=.04)$ and in a logistic regression analysis, adjusting for age and education, subjects with MCs were twice as likely to have questionable dementia compared with subjects without MCs (odds ratio [OR], 2.1; 95\% confidence interval [CI], 0.9-4.9), but this was not statistically significant.

We restricted our analyses of follow-up data to the 80 subjects who had denied MCs at the initial evaluation (Table 2). At follow-up, 21 subjects had new MCs. There were no significant differences in age, education, sex, or language between those with and without new MCs. Subjects with new MCs performed significantly worse than persistent noncomplainers on all 3 memory tests: Total Recall Test $(P=.04)$, Delayed Recall Test $(P=.003)$, and Visual Recognition Test $(P=.006)$. Nine ( $43 \%)$ of the 21 subjects with new MCs met criteria for questionable dementia $(n=5)$ or dementia $(n=4)$ at follow-up, of whom 5 had questionable dementia at baseline. Only 9 (15\%) of the 59 subjects without MCs met criteria for questionable dementia $(n=7)$ or dementia $(n=2)$ at follow-up, including 4 with questionable dementia at baseline $\left(\chi^{2}, P=.007\right)$. In a logistic regression analysis adjusted for age and education, subjects with new MCs were nearly 5 times more likely to have significant cognitive impairment (questionable dementia or dementia) than subjects without MCs (OR, 4.5; 95\% CI, 1.3-15.4).

\begin{tabular}{|c|c|c|c|}
\hline Characteristics & $\begin{array}{c}\text { Subjective } \\
\text { Memary } \\
\text { Complaints } \\
\text { (n=53) }\end{array}$ & $\begin{array}{l}\text { No } \\
\text { Memory } \\
\text { Complaint } \\
(n=80)\end{array}$ & Total \\
\hline Gender, No. $(\%)$ female & $46(87)$ & $59(74)$ & $105(79)$ \\
\hline Mean (SD) age, $y$ & $75.0(6.7)$ & $75.3(7.2)$ & $75.2(7.0)$ \\
\hline Mean (SD) education, y & $6.6(4.1)$ & $8.0(4.2)$ & $74(4.2)$ \\
\hline Language, No (\%) English & $22(41)$ & $41(51)$ & $63(47)$ \\
\hline $\begin{array}{l}\text { Total Recall Test score, } \\
\text { mean (SD) }\end{array}$ & $34.6(8.4)$ & $35.1(8.2)$ & $34.9(8.2)$ \\
\hline $\begin{array}{l}\text { Delayed Recall Test score, } \\
\text { mean (SD) }\end{array}$ & $4.6(2,0)$ & $4.7(2.2)$ & $4.7(2.1)$ \\
\hline $\begin{array}{l}\text { Visual Recognition Test score, } \\
\text { mean (SD) }\end{array}$ & $10.3(18)$ & $10.7(1.6)$ & $10.5(1.7)$ \\
\hline $\begin{array}{l}\text { Questionable dementia, } \\
\text { No. }(\%)\end{array}$ & $19(35)^{*}$ & $16(20)$ & $35(26)$ \\
\hline
\end{tabular}

$* P<.05$.

There was also a trend for subjects with new MCs to show cognitive decline from baseline to follow-up, relative to subjects without MCs, as indicated by the results of the following analyses. New MCs were associated with a significant decline in scores on the Visual Recognition Test $(\mathrm{F}[1,75]=6.46, P=.01)$ and in the Delayed Recall Test $(\mathrm{F}[1,75]=3.9, P=.05)$, and there was a statistically nonsignificant decline in scores on the Total Recall Test $(F[1,75]=1.66, P=.2)$. In the logistic regression analysis, 
additional information that may have been available through the hospital record system, were used to reach a consensus diagnosis. Initial and follow-up evaluations were reviewed similarly. The National Institute of Neurological and Communicative Disorders and Stroke-Alzheimer's Disease and Related Disorders Association criteria were used for the diagnosis of probable or possible Alzheimer disease. ${ }^{30}$ Subjects who met our criteria for dementia received a Clinical Dementia Rating (CDR) ${ }^{31}$ of 1 or more to reflect the severity of the dementia. Subjects who just failed to meet our criteria for dementia and subjects who met our neuropsychological criteria for dementia but lacked evidence of functional impairment were assigned a CDR of 0.5 , indicating questionable dementia. Subjects with a CDR of 0 were referred to as normal.

\section{Inclusion Criteria}

Subjects were included in the current study if they completed both the baseline and 1-year follow-up evaluations, if they did not meet our criteria for dementia at the baseline evaluation, and if no informant had contributed to the history taken by the neurologist at the initial or follow-up evaluations. This ensured that all MCs were by self-report.

\section{STATISTICAL ANALYSIS}

\section{Baseline Analyses}

We compared subjects with baseline MCs with those without baseline MCs with respect to gender, age, education, test language, performance on memory tests, and CDR using $t$ tests or $\chi^{2}$. We performed a logistic regression analysis to assess the association between MCs and significant cognitive impairment, adjusting for age and education.

Follow-up Analyses

We restricted follow-up analyses to subjects who had denied MCs at the initial evaluation. We compared the group with MCs at follow-up with the group without MCs at follow-up with respect to gender, age, education, test language, memory test performance, and CDR at follow-up using $t$ tests or $\chi^{2}$. We then performed logistic regression analyses to assess new MCs as a predictor of significant cognitive impairment (questionable dementia or dementia) at follow-up, adjusting for age and education. Finally, we investigated the association between new MCs and cognitive decline by assessing the change over 1 year in individual memory test scores and the change in the CDR. To assess memory score change over 1 year, we performed analyses of variance in which the follow-up memory test score was the variable of interest and new MCs the independent variable, adjusting for age, education, and the baseline memory test score. These analyses were repeated for each of the 3 memory tests. To assess the association of new $M C s$ with change in the CDR, we performed a logistic regression analysis. The outcome of interest in this analysis was change in CDR, dichotomized into decline (ie, follow-up CDR more than baseline CDR) or stability (ie, follow-up CDR less than or equal to baseline CDR). In this analysis, the presence of MCs at follow-up (yes or no) was the independent variable of interest and we adjusted for baseline CDR (ie, 0 or 0.5 ), age, and education.

\begin{tabular}{|c|c|c|c|}
\hline Characteristics & $\begin{array}{c}\text { Memary } \\
\text { Complaints } \\
(n=21)\end{array}$ & $\begin{array}{c}\text { No Wemory } \\
\text { Complaint } \\
(\mathrm{n}=59)\end{array}$ & $\begin{array}{l}\text { Total } \\
(\mathrm{N}=80)\end{array}$ \\
\hline Gender, No. $(\%)$ female & $15(71)$ & $44(75)$ & $59(74)$ \\
\hline Mean (SD) age, y & $76.8(6.5)$ & $76.17 .5)$ & $76.3(7.2)$ \\
\hline Mean (SD) education, y & $77(4.4)$ & $8.1(4.2)$ & $8.0(4.2)$ \\
\hline Language, No (\%) English & $10(48)$ & $31(53)$ & $41(51)$ \\
\hline $\begin{array}{l}\text { Total Recall Test score, } \\
\text { mean (SD) }\end{array}$ & $31.7(10.0) t$ & $362(79)$ & $35.0(8.7)$ \\
\hline $\begin{array}{l}\text { Delayed Recall Test score, } \\
\text { mean (SD) }\end{array}$ & $3.1(2.0)+$ & $4.9(2.3)$ & $4.4(2.3)$ \\
\hline $\begin{array}{l}\text { Benton recognition score, } \\
\text { mean (SD) }\end{array}$ & $9.1(2.3) \neq$ & $10.6(1.9)$ & $10.2(21)$ \\
\hline $\begin{array}{l}\text { Questionable dementia, } \\
\text { or dementia, No }(\%)\end{array}$ & $9(43) \neq$ & $9(15)$ & $18(22)$ \\
\hline
\end{tabular}

*All subjects denied memory complaints at baseline evaluation. $+\mathrm{P}<.05$.

$\ddagger P<.01$.

new MCs were associated with a 3-fold risk of decline in $\mathrm{CDR}$, relative to controls, although this failed to reach levels of statistical significance (OR, 3.0; 95\% CI, 0.7-12.7).

\section{COMMENT}

Herein, MCs at baseline were not associated with poor memory test performance and only weakly associated with significant cognitive impairment. By contrast, new-onset
MCs at follow-up were strongly associated with poor memory test performance and significant cognitive impairment. New MCs were also associated with decline in cognitive performance over the year of follow-up. Our results suggest that MCs from individuals who previously denied memory problems may more validly reflect poor memory or cognition than MCs when no such history is available.

Our analyses were restricted to subjects who provided their own history, a necessary design feature, since the goal was to assess the validity of incident subjective MCs, but one that may have introduced biases into the study. The sample derived from a study of elderly individuals who were users of health care services and agreed to participate in our study, and we must be cautious about generalizing these findings to a different population. It is important to determine if similar results emerge from longitudinal, population-based studies of randomly selected, elderly individuals. The history of MCs was elicited by a simple inquiry without additional well-defined probes. While this may represent a limitation, the nature of the screening question corresponds to the kind of inquiry a clinician might make during the course of a general practice consultation.

Memory complaints have failed to be useful predictors of memory dysfunction in community or clinicbased studies because many individuals with MCs lack evidence of memory impairment and some individuals with objective memory impairment deny MCs. Individuals with MCs might lack objective evidence of memory impair- 
ment for many reasons. One possibility is that individuals report MCs when they perceive a change in their memory performance, but the decline is insufficient to produce measurable abnormalities on neuropsychological tests owing to the inappropriateness or insensitivity of the instrument or because there is a considerable range over which performance is accepted as normal. Most community-based studies ${ }^{2-8,12-14}$ have been cross-sectional in design and could not, therefore, detect decline in individuals' memory performance. However, several longitudinal studies have demonstrated relatively stable memory performance in most subjects with persisting MCs whose cognition was initially normal, ${ }^{9-11}$ indicating that MCs must often reflect phenomena other than memory decline. In some instances, MCs might reflect the subject's awareness of difficulties in nonmemory cognitive domains. For instance, word-finding difficulties or visuospatial problems might be perceived as memory problems. Numerous studies ${ }^{5-8,13,14}$ have demonstrated that MCs may be associated with depression rather than memory impairment. Other studies ${ }^{3,15,16}$ have identified certain personality characteristics, such as neuroticism or a tendency toward somatic complaining (presumably relatively stable), that appear to be associated with a tendency to report MCs.

Individuals with impaired memory might deny having MCs for a variety of reasons. In a cross-sectional study comprising individuals with cognition ranging from normal to moderately demented, Grut et $\mathrm{al}^{8}$ showed that the prevalence of MCs increased with increasing levels of cognitive impairment up to the point of early dementia then declined, suggesting that insight for personal cognitive problems declines as cognitive impairment becomes more advanced. Personality, gender, or cultural characteristics might also hypothetically lead an individual to deny cognitive symptoms of which he or she is actually aware.

In our study, we compared the memory test performance and cognition of incident complainers with those of persistent noncomplainers, all of whom were without dementia at baseline. We believe that this study design was key to demonstrating validity of MCs in our sample. By restricting the initial sample to subjects who were without dementia, we excluded individuals who might have denied having MCs because of poor insight secondary to dementia. By restricting our analysis of follow-up data to subjects who denied having MCs initially, we presumably excluded some individuals who may have persistently reported MCs because of relatively invariant personality traits, cultural characteristics, or chronic depression. In this restricted sample, new MCs were significantly associated with poor memory test performance and cognitive impairment.

How relevant are our observations to the practicing clinician? Our study is analogous to a clinical setting in which elderly subjects who are seen on a regular basis are asked the screening question, "Do you have any problems with your memory?" That is, our study is most pertinent to a situation in which clinicians actively elicit MCs rather than one in which subjects actively seek help for memory problems. Clinical judgment dictates how far to pursue a symptom elicited by screening. However, our results suggest that individuals who have previously denied having MCs but now admit to them might warrant particular concern from the clinician.
Accepted for publication January 28, 1997.

This work was supported by federal grants AG07232, AG10963, AG08702, and RR00645 from the National Institutes of Health, Bethesda, Md, and by the Charles S. Robertson Memorial Gift for Alzheimer's Disease Research from the Banbury Fund.

Reprints: Yaakov Stern, PhD, Gertrude H. Sergievsky Center, Columbia University, $630 \mathrm{~W} 168$ th St, New York, NY 10032.

\section{REFERENCES}

1. McCormick WC, Kukull WA, van Belle G, Bowen JD, Teri L, Larson E. Symptom patterns and comorbidity in the early stages of Alzheimer's disease. J Am Geriatr Soc. 1994;42:517-521.

2. Jorm AF, Christensen $H$, Henderson AS, Korten $A E$, Mackinnon AJ, Scott $R$. Complaints of cognitive decline in the elderly. Psychol Med. 1994;24:365-374.

3. Hanninen $T$, Reinikainen KJ, Helkala $E-L$, et al. Subjective memory complaints and personality traits in normal elderly subjects. J Am Geriatr Soc. 1994;42:1-4.

4. Gagnon M, Dartigues JF, Mazaux JM, et al. Self-reported memory complains and memory performance in elderly French community residents: results of the PAQUID research program. Neuroepidemiology. 1994;13:145-154.

5. Bolla KI, Lindgren XN, Bonaccorsy C, Bleecker ML. Memory complaints in older adults: fact or fiction? Arch Neurol. 1991;48:61-64.

6. O'Connor DW. Pollitt PA, Roth M, Brook PB, Reiss BB. Memory complaints and impairment in normal, depressed, and demented elderly persons identified in a community survey. Arch Gen Psychiatry. 1990;47:224-227.

7. Bassett SS, Folstein MF. Memory complaint, memony performance, and psychiatric diagnosis. J Geriatr Psychiatry Neurol. 1993;6:105-111.

8. Grut M, Jorm A, Fratiglioni L, Forsell Y, Viitanen M, Winblad B. Memory complaints of elderly people in a population survey: variation according to dementia stage and depression. J Am Geriatr Soc. 1993;41:1295-1300.

9. Flicker C, Ferris SH, Reisberg B. A longitudinal study of cognitive function in elderly persons with subjective memory complaints. J Am Geriatr Soc. 1993; 41:1029-1032.

10. Taylor JL, Miller TP, Tinklenberg JR. Correlates of memory decline. Psychol Aging. 1992;7:185-193.

11. O'Brien JT, Beats B, Hill K, Howard R, Sahakian B, Levy R. Do subjective memory complaints precede dementia? Int J Geriatr Psychiatry. 1992;7:481-486.

12. Christensen $\mathrm{H}$. The validity of memory complaints by elderly persons. Int $J$ Geriatr Psychiatry. 1991;6:307-312.

13. Kahn RL, Zarit SH, Hilbert NM, Niederehe G. Memory complaint and impairment in the aged. Arch Gen Psychiatry. 1975;32:1569-1573.

14. Plotkin DA, Mintz $\downarrow$, Jarvik LF. Subjective memory complaints in geriatric depression. Am J Psychiatry. 1985;142:1103-1105.

15. Zonderman $A$, Costa $P$, Kawas $C$. Personality predicts complaints of benign memory loss. Neurology. 1989;39(supp| 1):194

16. Poitrenaud J, Malbezin M, Guez D. Self-rating and psychometric assessment of age-related changes in memory among young-elderly managers. Dev Psychol. 1989;5:285-294.

17. Gurland $B$, Wilder $D$, Cross $P$, et al. Relative rates of dementia by multiple case definitions, over two prevalence periods, in three sociocultural groups. Am J Geriatr Psychiatry. 1995;3:6-20.

18. Wilder $D$, Cross $P$, Chen $J$, et al. Operating characteristics of brief screens for dementia in a multicultural population. Am J Geriatr Psychiatry. 1995;3:96-107.

19. Gurland B, Wilder D. The 'CARE' interview revisited: development of an efficient, systematic, clinical assessment. J Gerontol. 1984;39:129-137.

20. Stern $Y$, Andrews $H$, Pittman $J$, et al. Diagnosis of dementia in a heterogeneous population. Arch Neurol. 1992;49:453-460.

21. Buscke $H$, Fuld PA. Evaluating storage, retention, and retrieval in disordered memory and learning. Neurology. 1974;24:1019-1025.

22. Benton AL. The Visual Retention Test. New York, NY: The Psychological Corp; 1955.

23. Folstein MF, Folstein SE, McHugh PR. Mini-Mental State. J Psychiatr Res. 1975; 12:189-198.

24. Wechsler D. Wechsier Adult Intelligence Scale, Revised. New York, NY: The Psychological Corp; 1981.

25. Mattis S. Mental status examination for organic mental syndrome in the elderly patient. In: Bellak L, Karasu TB, eds. Geriatric Psychiatry. New York, NY: Grune \& Stratton Inc; 1976.

26. Kaplan E, Goodglass H, Weintraub S. Boston Naming Test. Philadelphia, Pa: Lea \& Febiger; 1983.

27. Benton AL, Hamsher KD. Multilingual Aphasia Examination, Revised. lowa City: University of lowa; 1978

28. Goodglass H, Kaplan D. The Assessment of Aphasia and Related Disorders. 2nd ed. Philadelphia, Pa: Lea \& Febiger; 1981.

29. The Rosen Drawing Test. Bronx, NY: Veterans Affairs Medical Center; 1981.

30. McKhann G, Drachman D, Folstein M, Katzmann R, Price D, Stadlan EM. Clinical diagnosis of the Alzheimer's disease. Neurology. 1984;34:939-944.

31. Burke WJ, Miller JP, Rubin EH, et al. The reliability of the Washington University Clinical Dementia Rating. Arch Neurol. 1988;45:31-32. 